University of Nebraska - Lincoln

DigitalCommons@University of Nebraska - Lincoln

Publications from USDA-ARS / UNL Faculty

U.S. Department of Agriculture: Agricultural

Research Service, Lincoln, Nebraska

2018

\title{
Suppression of Aflatoxin Production in Aspergillus Species by Selected Peanut (Arachis hypogaea) Stilbenoids
}

Victor S. Sobolev

USDA-ARS National Peanut Research Laboratory, Victor.Sobolev@usda.gov

R. S. Arias

USDA-ARS National Peanut Research Laboratory, Dawson, GA, renee.arias@usda.gov

Kerestin Goodman

National Peanut Research Laboratory, USDA-ARS

Travis Walk

National Peanut Research Laboratory, USDA-ARS, travis.walk@ars.usda.gov

Valerie Orner

National Peanut Research Laboratory, USDA-ARS, valerie.orner@ars.usda.gov

See next page for additional authors

Follow this and additional works at: https://digitalcommons.unl.edu/usdaarsfacpub

Part of the Agricultural Science Commons, Agriculture Commons, and the Agronomy and Crop

Sciences Commons

Sobolev, Victor S.; Arias, R. S.; Goodman, Kerestin; Walk, Travis; Orner, Valerie; Faustinelli, Paola C.; and Massa, Alicia, "Suppression of Aflatoxin Production in Aspergillus Species by Selected Peanut (Arachis hypogaea) Stilbenoids" (2018). Publications from USDA-ARS / UNL Faculty. 1812.

https://digitalcommons.unl.edu/usdaarsfacpub/1812

This Article is brought to you for free and open access by the U.S. Department of Agriculture: Agricultural Research Service, Lincoln, Nebraska at DigitalCommons@University of Nebraska - Lincoln. It has been accepted for inclusion in Publications from USDA-ARS / UNL Faculty by an authorized administrator of DigitalCommons@University of Nebraska - Lincoln. 


\section{Authors}

Victor S. Sobolev, R. S. Arias, Kerestin Goodman, Travis Walk, Valerie Orner, Paola C. Faustinelli, and Alicia Massa 


\title{
Suppression of Aflatoxin Production in Aspergillus Species by Selected Peanut (Arachis hypogaea) Stilbenoids
}

\author{
Victor Sobolev,*ํำ Renee Arias, Kerestin Goodman, Travis Walk, Valerie Orner, Paola Faustinelli, \\ and Alicia Massa \\ National Peanut Research Laboratory, Agricultural Research Service, United States Department of Agriculture, P.O. Box 509, Dawson, \\ Georgia 39842, United States
}

ABSTRACT: Aspergillus flavus is a soil fungus that commonly invades peanut seeds and often produces carcinogenic aflatoxins. Under favorable conditions, the fungus-challenged peanut plant produces and accumulates resveratrol and its prenylated derivatives in response to such an invasion. These prenylated stilbenoids are considered peanut antifungal phytoalexins. However, the mechanism of peanut-fungus interaction has not been sufficiently studied. We used pure peanut stilbenoids arachidin-1, arachidin-3, and chiricanine A to study their effects on the viability of and metabolite production by several important toxigenic Aspergillus species. Significant reduction or virtually complete suppression of aflatoxin production was revealed in feeding experiments in A. flavus, Aspergillus parasiticus, and Aspergillus nomius. Changes in morphology, spore germination, and growth rate were observed in A. flavus exposed to the selected peanut stilbenoids. Elucidation of the mechanism of aflatoxin suppression by peanut stilbenoids could provide strategies for preventing plant invasion by the fungi that produce aflatoxins.

KEYWORDS: peanut, Arachis hypogaea, groundnut, phytoalexin, stilbenoid, arachidin-1, arachidin-3, chiricanine A, aflatoxin, aflatoxin production, aflatoxin suppression, aflatoxin inhibition, Aspergillus, Aspergillus flavus, Aspergillus parasiticus, Aspergillus nomius

\section{INTRODUCTION}

Aflatoxins are among the most potent human and animal carcinogens known in nature. ${ }^{1}$ It is estimated that over half of the world's population is chronically exposed to aflatoxins 710 (Figure 1). ${ }^{2}$ Preharvest aflatoxin contamination of peanuts caused by the toxigenic soil fungi Aspergillus flavus and Aspergillus parasiticus has been a serious health and economic problem since the early 1960s, the period of aflatoxin discovery. ${ }^{3,4}$ Slow progress in resolving the issue is explained mainly by the complexity of peanut-fungus interactions. ${ }^{5,6}$ The mechanism of peanut defense is poorly understood, although there is sufficient evidence that the peanut plant protects itself from fungal invasion by promptly producing stilbene-derived phytoalexins. $^{6-8}$ Fungi, in turn, produce phytoalexin-detoxifying enzymes to successfully invade the plant host. ${ }^{5}$ The involvement of fungal secondary metabolites in these intricate interactions has not been explored. However, the actions of peanut-derived resveratrol and various antioxidative compounds on A. flavus morphology and toxin formation has been reported by different scientific groups. ${ }^{9-11}$ Caffeic acid, 1 (Figure 1), at a $12 \mathrm{mM}$ concentration added to a fat-based growth medium reduced $>95 \%$ of aflatoxin production by $A$. flavus NRRL 3357, without affecting fungal growth. ${ }^{10}$ The action of caffeic acid ${ }^{10}$ and other antioxidants tested (gallic and tannic acids and methyl gallate) was attributed to the alleviation of oxidative stress in fungi. ${ }^{11}$ Treatment of A. flavus with resveratrol, 2 (Figure 1), decreased aflatoxin production and the formation of conidia, the asexual spores of a fungus. In addition, this stilbenoid caused abnormal mycelial development and directly inhibited the expression of aflatoxin-biosyntheticpathway cluster genes. ${ }^{9}$ Resveratrol content in resistant peanut lines was significantly higher than that in susceptible lines. At the same time, aflatoxin content was lower in the resistant lines compared with that in the susceptible lines. ${ }^{12}$ Based on that negative correlation, the authors suggested that resveratrol is strongly related to the resistance to aflatoxin production in peanut seeds. However, the production of resveratrol in peanut seeds is often accompanied by a prompt accumulation of prenylated stilbenoids ${ }^{13}$ with significantly higher antifungal activities compared with resveratrol. ${ }^{14}$ The authors did not report any prenylated stilbenoids in their samples, although the presence of these kinds of compounds is very likely on the basis of reports from research groups. ${ }^{5,13,15}$ A contribution to aflatoxin inhibition by these stilbenoids is also expected. However, the information on this issue is lacking.

The objective of the present research was to evaluate the abilities of some peanut prenylated stilbenoids (arachidin-1, 3; arachidin-3, 5; and chiricanine A, 6) to influence aflatoxin production in selected strains of important aflatoxin producers, namely, A. flavus, A. parasiticus, and A. nomius.

\section{MATERIALS AND METHODS}

Reagents, Materials, and Basic Apparatus. The HPLC-grade solvents used in the preparation of mobile phases and separations on silica gel were obtained from Fisher (Suwanee, GA). The HPLC-grade $\mathrm{H}_{2} \mathrm{O}$ was prepared with a ZD20 four-bowl Milli-Q water system (Millipore, Burlington, MA). The HPLC-grade methanol used for media extraction was purchased from VWR (Suwanee, GA), and 48well cell-culture plates (Nunc, Roskilde, Denmark) were used in all feeding experiments.

Reference Compounds. Pure, individual stilbenoids transarachidin-1, 3; trans-arachidin-2, 4; and trans-arachidin-3, 6, were

Received: October 3, 2017

Revised: November 29, 2017

Accepted: December 5, 2017

Published: December 5, 2017 


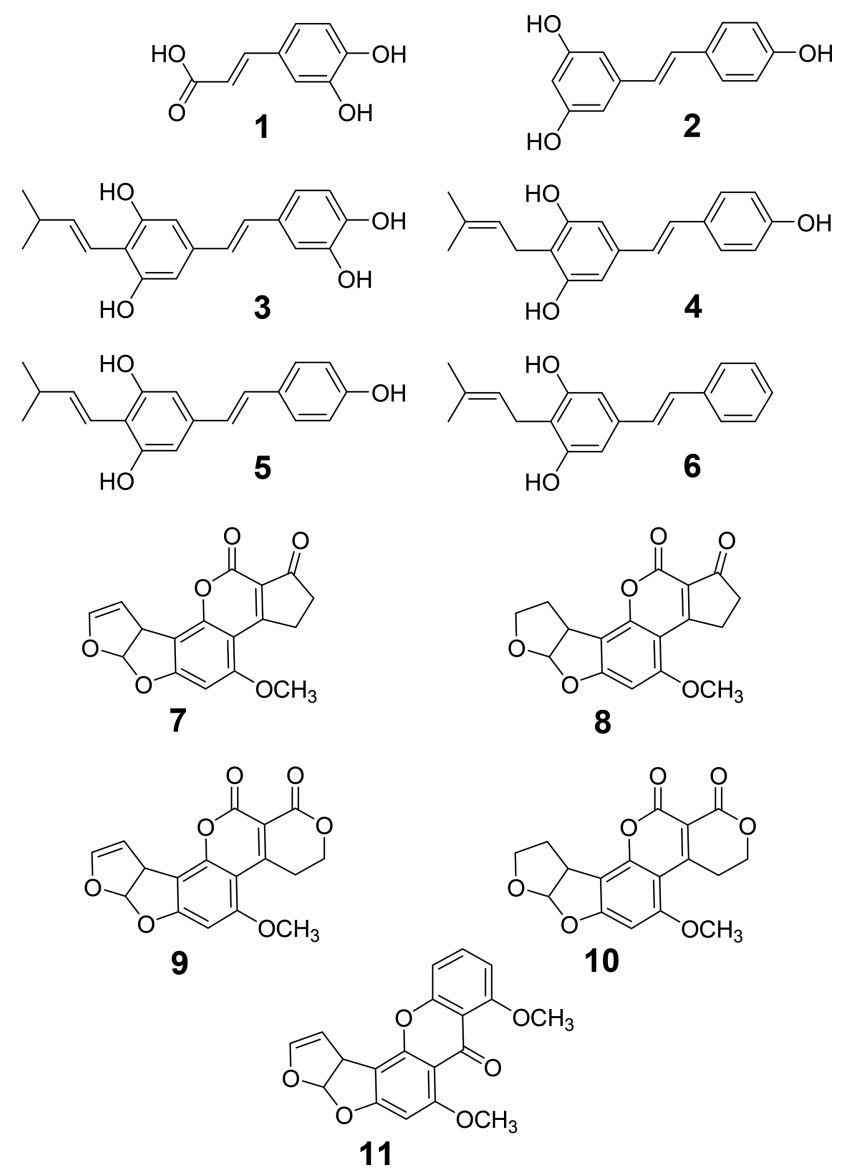

Figure 1. Structures of compounds discussed in the text. 1, transcaffeic acid; 2, trans-resveratrol; 3, trans-arachidin-1; 4, trans-arachidin2; 5, trans-arachidin-3; 6, chiricanine $A ; 7$, aflatoxin $B_{1} ; 8$, aflatoxin $B_{2}$; 9, aflatoxin $\mathrm{G}_{1} ; 10$, aflatoxin $\mathrm{G}_{2} ; 11, O$-methyl sterigmatocystin.

obtained as previously described ${ }^{16}$ except that preparative HPLC was used as a final purification step rather than preparative TLC. HPLC separation was achieved by using a $100 \times 19 \mathrm{~mm}$ i.d., $5 \mu \mathrm{m}$, XTerra Prep RP18 OBD column (Waters, Milford, MA) and an isocratic mobile phase composed of $\mathrm{CH}_{3} \mathrm{CN}, 2 \% \mathrm{HCOOH}$ in $\mathrm{H}_{2} \mathrm{O}$, and $\mathrm{H}_{2} \mathrm{O}$ (55, 3, and $42 \%$, respectively). The flow rate was $8.0 \mathrm{~mL} / \mathrm{min}^{17}$ Chiricanine A, 6, was prepared as described ${ }^{17}$ (Figure 1). O-Methyl sterigmatocystin was purchased from Cayman Chemical (Ann Arbor, $\mathrm{MI}$ ), and a certified solution of combined aflatoxins $B_{1}, 7 ; B_{2}, 8 ; G_{1}, 9$; and $\mathrm{G}_{2}, 10$, was purchased from Supelco (Bellefonte, PA).

Fungi. A. flavus NRRL 3357, A. flavus NRRL 29487, A. nomius NRRL 13137, A. parasiticus NRRL 29580, and A. parasiticus 29602 were made available by the fungal collection of the National Peanut Research Laboratory, Agricultural Research Service (ARS), USDA (Dawson, GA).

Feeding Technique. The experiments comprised a total of 546 cell-culture wells $(2 \mathrm{~mL}$ each) containing the essential stilbenoids arachidin-1, 3; arachidin-3, 5; and chiricanine A, 6, at $0.3 \mathrm{mM}$ concentrations in $0.5 \mathrm{~mL}$ of potato dextrose broth or agar (each well received $46.8 \mu \mathrm{g}$ of arachidin-1, $44.4 \mu \mathrm{g}$ of arachidin-3, or $42.0 \mu \mathrm{g}$ of chiricanine A). To prepare the spiked potato dextrose agar (PDA), the stilbenoids were dissolved in $96 \% \mathrm{EtOH}$, added to an appropriate amount of molten PDA agar, and then cooled to $45-50{ }^{\circ} \mathrm{C}$, followed by intensive mixing with a magnetic stirrer. The concentration of EtOH in the media did not exceed $1 \%$. Twenty microliters of fungal spores $\left(10^{6} / \mathrm{mL}\right)$ were applied to each experimental well and thoroughly distributed on the surface of the agar with a glass rod. For comparison, a set of controls containing broth alone, broth with the individual phytoalexins but without the fungi, and broth with the individual fungi but without the phytoalexins was added to the experimental setup. All the experiments were performed in duplicate or triplicate. Samples were collected every $24 \mathrm{~h}$ and kept frozen at -28 ${ }^{\circ} \mathrm{C}$. The extraction of each sample was performed with $5 \mathrm{~mL}$ of $\mathrm{MeOH}$ at $22 \pm 2{ }^{\circ} \mathrm{C}$ for $18 \mathrm{~h}$ without agitation in the dark. The filtered extracts were evaporated to dryness in a stream of $\mathrm{N}_{2}$, redissolved in $300 \mu \mathrm{L}$ of $\mathrm{MeOH}$, and filtered again through a glass-fiber filter, and then aliquots of the filtrates were analyzed by HPLC-MS.

HPLC-DAD-MS Analyses. Separations of the well extracts were performed using a tandem HPLC-MS Surveyor system equipped with an MS Pump Plus, an Autosampler Plus, and a PDA Plus Detector (Thermo Electron Corporation, San Jose, CA) covering the 200-600 $\mathrm{nm}$ range, and a $100 \times 4.6 \mathrm{~mm}$ i.d., $3.5 \mu \mathrm{m}$, XSelect HSS C18 analytical column (Waters, Milford, MA) was used. $\mathrm{H}_{2} \mathrm{O}($ A), $\mathrm{MeOH}$ (B), and $2 \% \mathrm{HCOOH}$ in $\mathrm{H}_{2} \mathrm{O}$ (C) were used in the following gradient: the initial conditions were $59 \% \mathrm{~A} / 40 \% \mathrm{~B} / 1 \% \mathrm{C}$, which was changed linearly to $10 \% \mathrm{~A} / 89 \% \mathrm{~B} / 1 \% \mathrm{C}$ in $11 \mathrm{~min}$, changed to $0 \% \mathrm{~A} /$ $99 \% \mathrm{~B} / 1 \% \mathrm{C}$ in $0.01 \mathrm{~min}$, held isocratic for $3 \mathrm{~min}$, then changed to the initial conditions in $0.01 \mathrm{~min}$, and held for $4 \mathrm{~min}$ before the next injection. The flow rate was $1.2 \mathrm{~mL} / \mathrm{min}$. The column was maintained at $40{ }^{\circ} \mathrm{C}$.

The MS analyses were performed using a Finnigan LCQ Advantage MAX ion-trap mass spectrometer equipped with an ESI interface and operated with the Xcalibur version 1.4 software (Thermo Electron Corporation, San Jose, CA). The data were acquired in the full-scan mode (MS) from $m / z 100-2000$. The heated-capillary temperature was $250{ }^{\circ} \mathrm{C}$, the APCI-vaporizer temperature was $380^{\circ} \mathrm{C}$, the sheath gas flow was 60 units, the auxiliary gas flow was 5 units, the capillary voltage was $53 \mathrm{~V}$, and the source voltage was $4.5 \mathrm{kV}$. In the $\mathrm{MS}^{2}$ analyses, the $[\mathrm{M}+\mathrm{H}]^{+}$ions observed for each chromatographic peak in the full-scan analyses were isolated and subjected to source collision-induced dissociation (CID) using a He buffer gas. In all CID analyses, the isolation width, relative fragmentation energy, relative activation $Q$ and activation time were: $1.2,30$ or $35 \%, 0.25$, and $30 \mathrm{~ms}$, respectively. The concentrations of trans-arachidin-1, trans-arachidin-3, chiricanine A, and $\mathrm{O}$-methyl sterigmatocystin in the extracts were calculated by reference to the peak areas of the corresponding pure standards at 340, 335, 312, and $314 \mathrm{~nm}$, respectively. High concentrations of all aflatoxins were determined at $362 \mathrm{~nm}$. To determine the low concentrations of the toxins, the extracts were purified as previously described ${ }^{18}$ and subjected to aflatoxin analysis using an Acquity UPLC instrument equipped with a matching UPLC H-class Quaternary Solvent Manager; UPLC Sample Manager; UPLC Fluorescent Detector (FLR); and $50 \times 2.1 \mathrm{~mm}$ i.d., $1.7 \mu \mathrm{m}$, Acquity UPLC BEH C18 column (Waters, Milford, MA). The mobile phase was composed of a water $/ \mathrm{MeOH} / \mathrm{CH}_{3} \mathrm{CN}(64: 23: 13, \mathrm{v} / \mathrm{v} / \mathrm{v})$ mixture, and the flow rate was $0.25 \mathrm{~mL} / \mathrm{min}$. The column was maintained at 35 ${ }^{\circ} \mathrm{C}$ in the system column heater. The concentrations of the aflatoxins were determined by reference to the peak areas of the corresponding commercial standards (calibration curve). The detection limits were $0.15 \mathrm{ng} / \mathrm{g}$ for aflatoxins $G_{1}$ and $B_{1}$ and $0.02 \mathrm{ng} / \mathrm{g}$ for aflatoxins $G_{2}$ and $\mathrm{B}_{2}$.

Preparation of Medium and Estimation of Morphological Changes in A. flavus NRRL 3357. Spore germination and hyphal growth of Aspergillus flavus NRRL 3357 were monitored over $20 \mathrm{~h}$ in the presence of the individual peanut phytoalexins arachidin-3, arachidin-2, and chiricanine-A. Stock solutions of these phytoalexins were prepared separately at $150 \mathrm{mM}$ in ethanol and added to $5 \mathrm{~mL}$ test tubes containing $1 \mathrm{~mL}$ of potato dextrose broth (PDB), using only one phytoalexin per well at a final concentration of $0.3 \mathrm{mM} ; 2 \mu \mathrm{L}$ of ethanol was added to $1 \mathrm{~mL}$ of PDB to be used as a control. A. flavus NRRL3357 was grown on potato-dextrose-agar (PDA) medium for 6 days at $30{ }^{\circ} \mathrm{C}$, and its spores were harvested in sterile distilled water and passed through frits that were placed into a matching $1.5 \mathrm{~mL}$ SPE reservoir (both from Grace Davison Discovery Science, Deerfield, IL) in order to remove fragments of hyphae, the threadlike filaments forming the mycelium of a fungus. A suspension of $10^{6}$ spores $/ \mathrm{mL}$ was prepared in sterile distilled water, and $40 \mu \mathrm{L}$ of the spore suspension was added to each $5 \mathrm{~mL}$ test tube containing $1 \mathrm{~mL}$ of PDB supplemented with a phytoalexin and to the PDB control. For each phytoalexin and for the control, duplicate test tubes were used during 

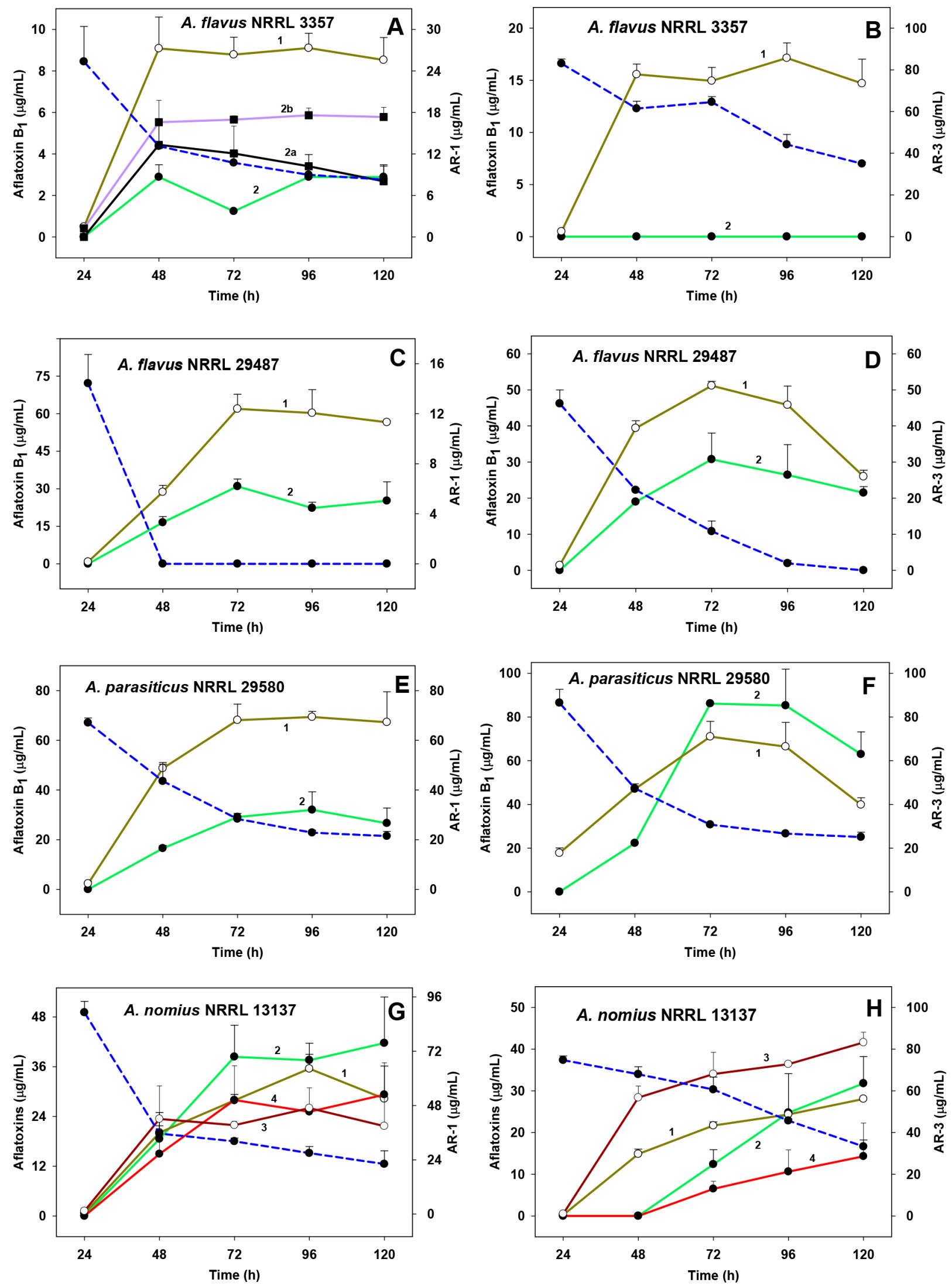

Figure 2. continued 

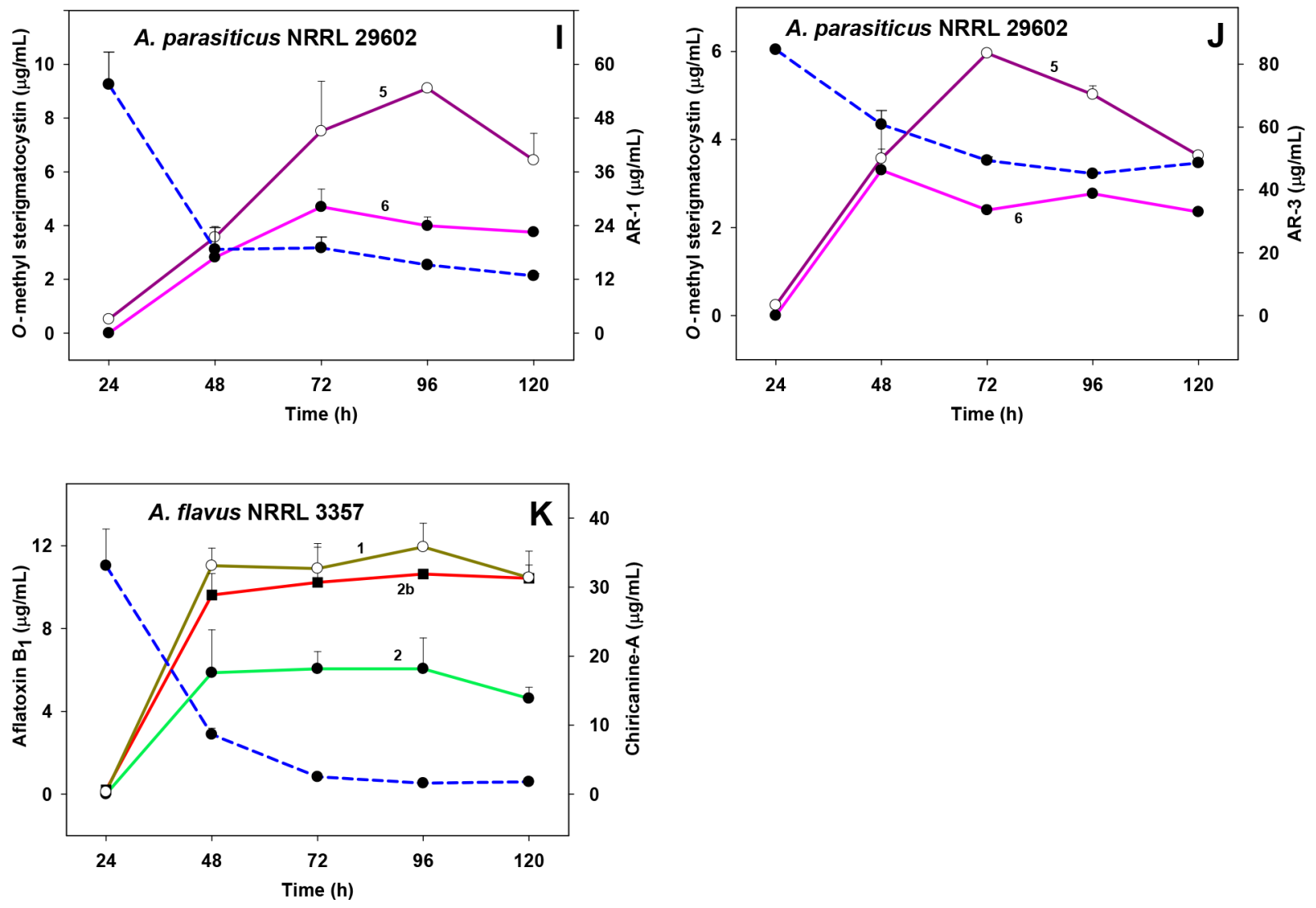

Figure 2. Dynamics of aflatoxin inhibition by peanut stilbenoids. Line 1 in all graphs represents aflatoxin $B_{1}$ formation in the control (without stilbenoids) samples. Line 2 in all graphs shows aflatoxin $B_{1}$ formation in the experimental samples. (A) Lines $2 a$ and $2 b$ show aflatoxin $B_{1}$, 7 , formation after the treatment with $0.15 \mathrm{mM}$ and $0.075 \mathrm{mM}$ arachidin-1, respectively. $(\mathrm{G}, \mathrm{H})$ Line 3 represents aflatoxin $\mathrm{G}_{1}, 9$, formation in the control samples (without the arachidins), and line 4 shows aflatoxin $G_{1}$ formation in the experimental samples. (IJ) Line 5 shows the dynamics of accumulation of $O$-methyl sterigmatocystin, 11, without the arachidins, and line 6 shows the concentrations of 11 in the experimental samples. (K) Line $2 \mathrm{~b}$ shows aflatoxin $\mathrm{B}_{1}$ formation after treatment with $0.075 \mathrm{mM}$ chiricanine $\mathrm{A}, 6$. In all graphs, dashed blue lines show the dynamics of the stilbenoid-concentration decline. AR-1 means arachidin-1, and AR-3 means arachidin-3.

the experiment. The inoculated test tubes were incubated at $30^{\circ} \mathrm{C}$ in the dark. Using wide bore tips, $12 \mu \mathrm{L}$ of each sample was collected at 2 $\mathrm{h}$ intervals starting after $6 \mathrm{~h}$ of incubation. The samples were observed under the microscope using a hemocytometer for spore counting, and hyphal-length quantitation was performed using the Live Measurement module of LAS software, ver. 4.3.0, in a Leica DM 2500 microscope (Vashaw Scientific Inc., Roswell, GA). Each sample was evaluated on 5-10 $\times 4 \mathrm{~nL}$ fields, and the number of fields was increased over time as the samples became more heterogeneous.

Data Analysis. Data were analyzed by ANOVA procedures using SAS 2000, ver. 7 (SAS Institute, Inc., Cary, NC). Multiple comparisons of the various means were carried out by the least significant difference (LSD) test at $p=0.05$. Comparisons of the means of two groups of data were performed using the $t$ test; the Mann-Whitney Rank Sum Test was applied when the normality test failed $(p<0.05)$.

\section{RESULTS AND DISCUSSION}

It is reasonable to suggest that there is appreciable inhibition of toxin formation in Aspergillus species by peanut prenylated stilbenoids on the basis of the published findings. ${ }^{9,10,14}$ To study the influence of peanut phytoalexins on aflatoxin accumulation, we used three prenylated stilbenoids, arachidin1, 3; arachidin-3, 5; and chiricanine A, 6 (Figure 1), in our feeding experiments. Because an insufficient quantity was available, another important stilbenoid, arachidin-2, 4, was used only in the morphological study. The rationale for the choice was based on the fact that arachidin-1, 3, and arachidin-3, 5, are the major prenylated stilbenoids that are formed in funguschallenged peanut seeds. In addition, these stilbenoids, as well as chiricanine A, 6, and arachidin-2, 4, demonstrated appreciable biological activity compared with the other stilbenoids tested. ${ }^{14}$ The soil fungi used in this research included five strains of Aspergillus that differed from each other by their metabolite profiles and toxigenic potential: A. flavus NRRL 3357, a moderate producer of aflatoxins $B_{1}(7)$ and $B_{2}$ (8); A. flavus NRRL 29487, a high producer of aflatoxins $B_{1}$ and $\mathrm{B}_{2} ; A$. nomius NRRL 13137, a high producer of aflatoxins $\mathrm{B}_{1}, \mathrm{~B}_{2}$, $\mathrm{G}_{1}$ (9), and $\mathrm{G}_{2}$ (10); A. parasiticus NRRL 29580, a very high producer of aflatoxins $\mathrm{B}_{1}, \mathrm{~B}_{2}, \mathrm{G}_{1}$, and $\mathrm{G}_{2}$; and $A$. parasiticus NRRL 29602, a producer of $O$-methyl sterigmatocystin (11). The data on the fungal toxigenic potentials (not listed here) were provided by Dr. B. Horn of the National Peanut Research Laboratory, ARS, USDA (Dawson, GA). Preliminary feeding experiments demonstrated that arachidins $\mathbf{3}$ and $\mathbf{5}$ as well as chiricanine A, 6, were substantially more potent inhibitors of aflatoxin formation than caffeic acid, $\mathbf{1},{ }^{10}$ and resveratrol, $2 .{ }^{9}$ Therefore, about a 30-40-fold lower initial concentration of each stilbenoid was suggested on the basis of their activity. The final concentration of $0.3 \mathrm{mM}$ was chosen on the basis of the highest full solubility of 3,5 , and 6 in the PDA medium. This concentration is equivalent to $88.8 \mu \mathrm{g} / \mathrm{mL}$ of arachidin- 3 and is about 50-fold lower than the concentrations of the fungusinduced stilbenoids detected in alive, wounded peanut seeds. ${ }^{13}$ 
The current research demonstrated that the selected stilbenoids were capable of inhibiting the formation of aflatoxins 7-10 and the precursor $O$-methyl sterigmatocystin, 11, in all of the Aspergillus species tested. The most dramatic results were obtained when A. flavus NRRL 3357 was grown in the presence of arachidin-3, 5 (Figure 2B). At all sampling times, aflatoxin accumulation was almost completely (>98\%) suppressed (line 2, Figure 2B), whereas the control without arachidin-3 (line 1) demonstrated substantial accumulation of aflatoxin $B_{1}, 7$, from 48 to $120 \mathrm{~h}$ of incubation. Aflatoxin $B_{2}, 8$, was also detected, but the insignificant productions of aflatoxin $B_{2}$ by the A. flavus strains and of aflatoxins $B_{2}$ and $G_{2}, 10$, by the A. parasiticus strains used in this research were not accounted for in the simplicity of the presentation. A gradual decrease of arachidin-3, 5, from its initial concentration of 88.8 to $35.0 \mu \mathrm{g} /$ $\mathrm{mL}$ occurred over the course of the experiment within $120 \mathrm{~h}$ (Figure 2B). A. flavus NRRL 3357 growth inhibition in the presence of arachidin-3 was obvious from 24 to $120 \mathrm{~h}$ of incubation compared with the growth of the control (Figure 3B). Both mycelial and conidial growth was compromised in the experimental wells. However, there is no sufficient evidence to conclude that aflatoxin inhibition occurred because of the compromised fungal growth and development. The morphological observations and measurements were performed after 6 $\mathrm{h}$ of incubation of A. flavus NRRL 3357 conidia with arachidin3 at $30^{\circ} \mathrm{C}$. At $6 \mathrm{~h}$ and throughout the course of the experiment, in the presence of arachidin-3, conidia formed clustered masses (Figures 4C), unlike the control samples without arachidin-3 (Figure 4A,B). After allowing the spores to germinate for 13 and $15 \mathrm{~h}$ in the presence of arachidin-3 (Figure 4C,D), a higher degree of the mycelial branching was demonstrated compared with that in the control, whose branching was not so obvious and frequent (Figure 4A,B). The white arrows show clusters of germinating and branching spores (Figure $4 \mathrm{C}$ ). The black arrows show hyphae, the branching filaments that form the fungal mycelium. Figure 5A shows that there was a significant difference in the degree of spore germination after 8 and $10 \mathrm{~h}$ of incubation. A significant difference in hyphal length was also observed from $8 \mathrm{~h}$ to the end of the experiment (Figure $5 \mathrm{~B}$ ).

A similar experiment with the same fungal strain, A. flavus NRRL 3357, but arachidin-1, 3, as an inhibitor (Figure 2A) at $0.3 \mathrm{mM}$ concentration, demonstrated that aflatoxin accumulation was detected from $24 \mathrm{~h}$ to the end of the experiment (line 2), although it was 4-5-fold lower compared with that in the control (line 1). Lower arachidin-1, 3, concentrations of $0.15 \mathrm{mM}$ (line 2a) (Figure 2A) and $0.075 \mathrm{mM}$ (line $2 \mathrm{~b}$ ) also inhibited aflatoxin accumulation in a concentration-dependent pattern. The concentration of arachidin-1 rapidly dropped from the initial 93.6 to $25.4 \mu \mathrm{g} / \mathrm{mL}$ at $24 \mathrm{~h}$ and then gradually declined to $8.3 \mu \mathrm{g} / \mathrm{mL}$ at $120 \mathrm{~h}$. The difference in growth of the treated and control set of samples was not obvious (Figure 3A).

A stronger aflatoxin producer, A. flavus NRRL 29487, grown on the medium spiked with arachidin-3, was also affected by the stilbenoid, but its aflatoxin-inhibition pattern (Figure 2D) differed from that of A. flavus NRRL 3357. The peak of aflatoxin production in the control as well as in the treated sample was observed at $72 \mathrm{~h}$, and then production gradually declined. Arachidin-3 concentration gradually dropped from the original concentration to zero within $120 \mathrm{~h}$. When treated with arachidin-1, the same strain showed a different toxinformation pattern, as seen from Figure 2C. Suppression of aflatoxin (2- to 3-fold) was observed from 72 to $120 \mathrm{~h}$. At the same time, the arachidin- 1 concentration rapidly dropped from
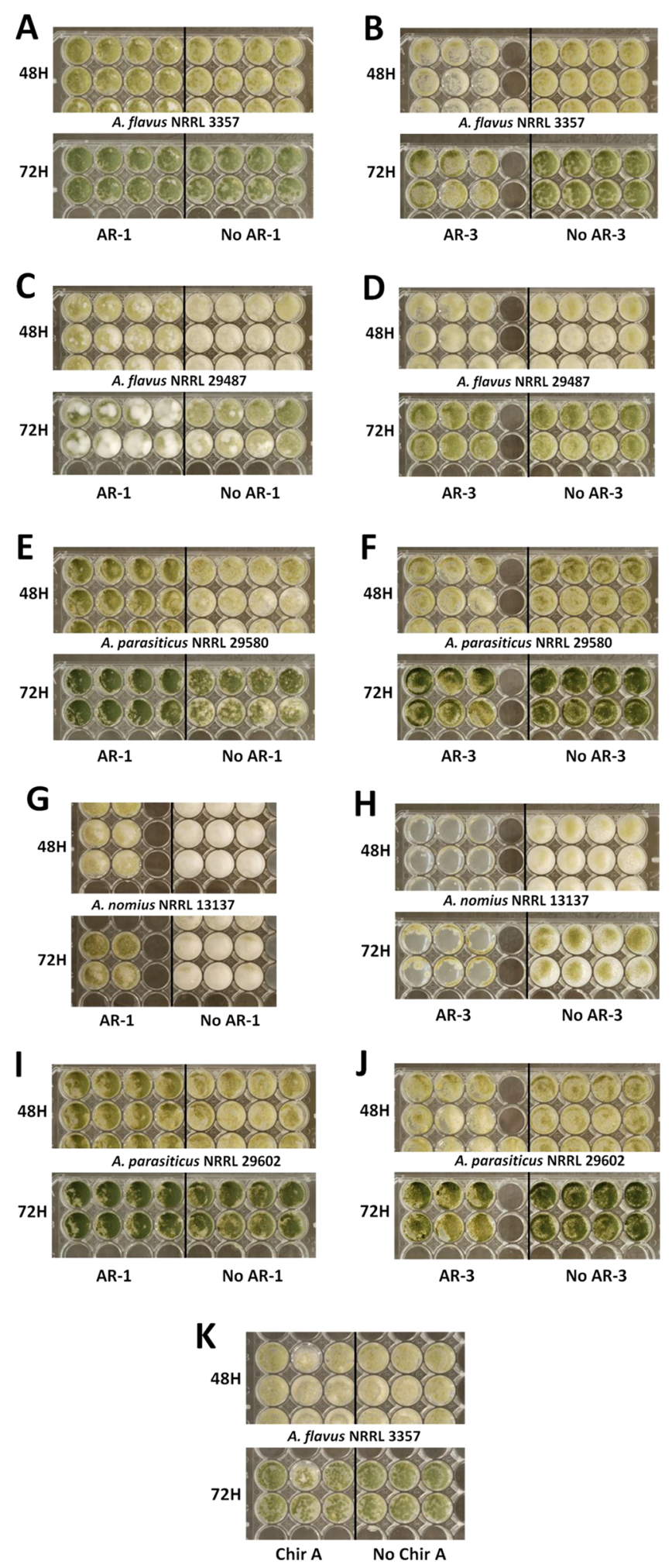

Figure 3. Experimental and control wells with the fungal species $A$. flavus, A. parasiticus, and A. nomius grown for 48 and $72 \mathrm{~h}$ on PDA medium with arachidin-1, 3 (B,D,F,H,J); arachidin-3, 5 (A,C,E,G,I); and with chiricanine A, $6(\mathrm{~K})$. AR-1 means arachidin-1, AR-3 means arachidin-3, and Chir A means chiricanine A.

the original concentration to almost zero at $48 \mathrm{~h}$ (Figure 2C). There was no visual difference in growth and development patterns between the control and the experiment in the case of arachidin-3 (Figure 3D), and only a slightly favorable formation 

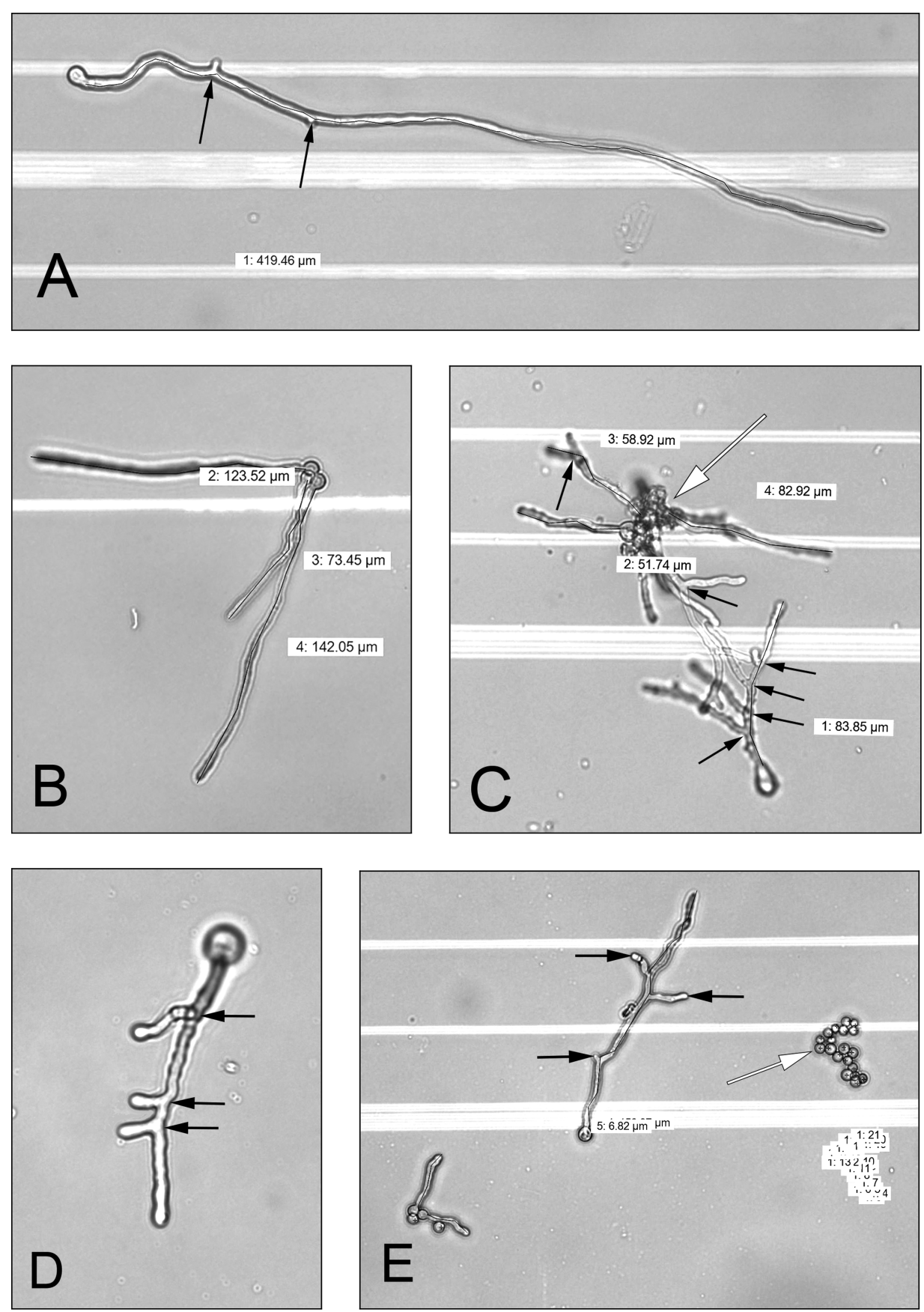

Figure 4. Microscopic view of the A. flavus NRRL 3357 fungal structures developed (A) without the stilbenoids (control) after $14 \mathrm{~h}$ of incubation; (B) without the stilbenoids (control) after $18.5 \mathrm{~h}$ of incubation; (C) with arachidin-3, 5, after $13 \mathrm{~h}$ of incubation; (D) with arachidin-3 after $15 \mathrm{~h}$ of incubation; and (E) with chiricanine A, 6, after $16 \mathrm{~h}$ of incubation. The black arrows show hyphae, the branching filaments that form the fungal mycelium; the white arrow shows a cluster of nonviable spores.

of conidia and mycelia was observed in the wells with arachidin1 (Figure 3C).

The growth and development of the highest aflatoxin producer tested, A. parasiticus NRRL 29580, was not affected by arachidin-3, 5 (Figure $3 \mathrm{~F}$ ). Also, there was no significant difference in aflatoxin inhibition between the control samples and samples with arachidin-3 (Figure 2F). However, aflatoxin suppression by arachidin-1, 3, was significant (about 3-fold) throughout the duration of the experiment with a concomitant decrease in the arachidin-1 concentration (Figure 2E). Although there was no distinct difference in appearance between the control and experimental wells with the fungus grown from 24 to $120 \mathrm{~h}$ in the absence or presence of arachidin-3, 5, respectively, (Figure 3F), there was a distinct difference when the fungus was treated with arachidin-1, 3. Surprisingly, more active fungal growth was observed in the wells treated with 3 compared with that in the control wells (Figure 3E). In addition, arachidin-1 seemed to promote conidial (green colored) formation rather than mycelial (white colored) formation from 48 to $120 \mathrm{~h}$.

Arachidin-1, 3, and arachidin-3, 5, displayed even more dramatic influences on fungal formation in A. nomius NRRL 13137 from 24 to $120 \mathrm{~h}$ (Figure 3G,H). Although the effect of arachidin-3 on fungal development was predictable, the effect of 

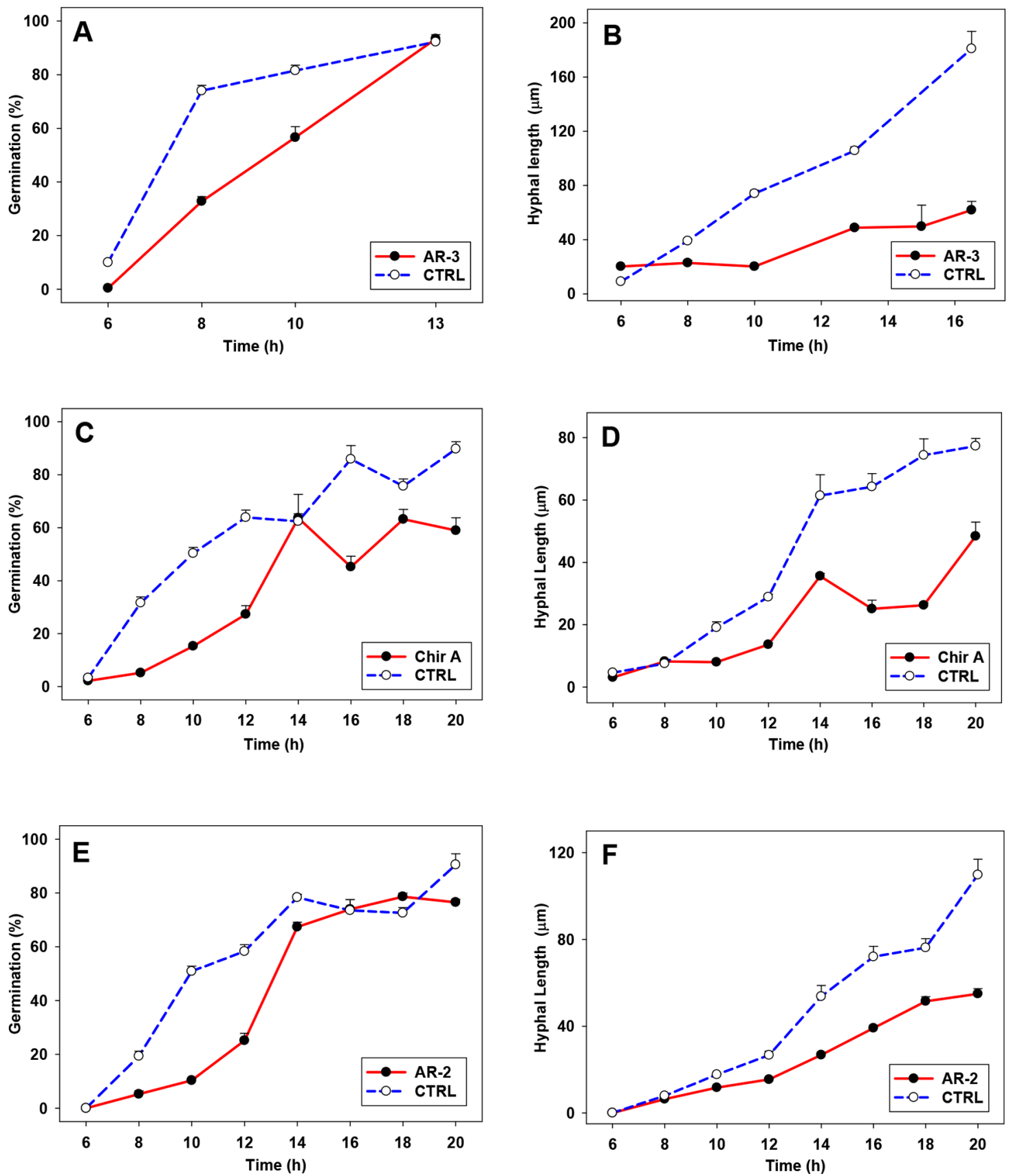

Figure 5. Morphological changes in A. flavus NRRL 3357 exposed to (A,B) arachidin-3, 5; (C,D) chiricanine A, 6; and (E,F) arachidin-2, 4. AR-3 means arachidin-3, Chir A means chiricanine A, and AR-2 means arachidin-2. CTRL means control.

arachidin-1 was unexpected. Arachidin-3 almost completely suppressed fungal formation at $48 \mathrm{~h}$ and substantially did so at later times (Figure 3H). In contrast, arachidin-1 favored conidial formation, whereas the control showed basically mycelial growth from 24 to $72 \mathrm{~h}$ of incubation (Figure $3 \mathrm{G}$ ). At the same time, the formation of all aflatoxins, $B_{1}, B_{2}, G_{1}$, and $G_{2}$, was not significantly inhibited by arachidin-1 (Figure $2 G$ ). On the other hand, arachidin-3 demonstrated appreciable activity and substantially inhibited the formation of aflatoxin $B_{1}$ at 48 and $72 \mathrm{~h}$ (Figure $2 \mathrm{H}$, lines 1 and 2 ) and significantly suppressed aflatoxin $G_{1}$ formation (lines 3 and 4). Degradation of arachidin-3 occurred at a slower rate compared with that of arachidin-1. The initial concentrations of 3, 5, and 6 in all the control samples remained unchanged within the statistical error throughout the course of the experiments. Therefore, the significant decrease of the stilbenoid concentrations in the presence of the fungi tested allows us to suggest that the most likely fate of 3,5 , and $\mathbf{6}$ is degradation by fungal enzymes. ${ }^{19}$

A natural $O$-methyl sterigmatocystin, 11, producer, $A$. parasiticus NRRL 29602, was also tested against the arachidins. It was reasonable to test the potential inhibition of $\mathbf{1 1}$ by the same stilbenoids as this mycotoxin is a precursor in the aflatoxin biosynthetic pathway. Both arachidin-1 and arachidin3 suppressed the formation of 11 most actively between 72 and $120 \mathrm{~h}$ of incubation (Figure 2I,J). At the same time, there were no noticeable differences between fungal growth and appearance at all times (Figure 3I,J) with the exception of slightly increased spore formation in the presence of 3 at $48 \mathrm{~h}$.

The limited quantity of chiricanine A, 6 , allowed us to test its action only on one strain, A. flavus NRRL 3357. In the presence 
of this stilbenoid, significant aflatoxin reduction was observed at all times starting at $48 \mathrm{~h}$ at $0.3 \mathrm{mM}$ (Figure $2 \mathrm{~K}$, line 2). Inhibition at $0.075 \mathrm{mM}$ was statistically insignificant but noticeable (Figure 2K, line 2b). The concentration of chiricanine A gradually reached a level of almost zero at $72 \mathrm{~h}$ from its original value of $84.0 \mu \mathrm{g} / \mathrm{mL}$. Visually, the control and experimental wells were indistinguishable at all times of fungal growth (Figure $3 \mathrm{~K}$ ). The morphological differences between the control and experimental samples of the fungus were obvious and significantly different in terms of germination rates and hyphal lengths (Figure 5C,D) starting at $8 \mathrm{~h}$ of incubation for the germination rates and $10 \mathrm{~h}$ for the hyphal lengths. At 6 $\mathrm{h}$, large numbers of spores clustered together (Figure 4E, white arrow) were observed in the presence of chiricanine $A$, whereas the control samples had single, loose spores. The fungal spores in the samples with chiricanine A stayed as clusters even after they started to form hyphae. In the samples with chiricanine A at $14-16 \mathrm{~h}$ of incubation, some branching was observed in the growing mycelia (Figure 4E). However, the branching was not as evident as it was in the experiments with arachidin-3. The control spores began to form clusters at $12 \mathrm{~h}$ of incubation, but the spore growth and elongation occurred without branching throughout the remainder of the observation (Figure 4B).

A pure sample of arachidin-2 was also tested using the same experimental setup. A. flavus NRRL 3357 treated with arachidin-2 demonstrated morphological changes (Figure $5 \mathrm{E}, \mathrm{F})$ similar to those that were observed with arachidin-3 and chiricanine A (Figure 5A-D). Conclusions on morphological changes were made on a statistically significant number of microscopic observations. The total number of fungal structures measured was 5496 in 329 fields of observation.

The present research demonstrated that the most abundant and highly biologically active peanut phytoalexins, arachidin-1, 3; arachidin-3, 5; and chiricanine A, 6, had appreciable capacity to inhibit aflatoxin formation in the important toxigenic Aspergillus species tested, A. flavus, A. parasiticus, and A. nomius. Aflatoxin inhibition was not necessarily accompanied by visible changes in fungal growth and development. At present, a mechanism of aflatoxin inhibition by peanut stilbenoids in Aspergillus cannot be suggested. Additional experiments with a larger number of peanut stilbenoids and fungal species may help to elucidate the stilbenoid structure-aflatoxin inhibition relationship. New in vivo research is also needed to ensure that aflatoxin inhibition occurs in the course of the peanut-fungus interaction. Such research is planned. Knowledge on the mechanism of the plant-fungus interaction could lead to new strategies for preventing plant invasion by the fungi that produce aflatoxins.

\section{AUTHOR INFORMATION}

\section{Corresponding Author}

*Tel.: +1 229995 7446, Fax: +1 229995 7416, E-mail: victor. sobolev@ars.usda.gov.

\section{ORCID}

Victor Sobolev: 0000-0001-5352-9539

\section{Funding}

This work was supported by USDA-ARS project numbers 6044-42000-010-00D and 6604-21000-003-00D.

\section{Notes}

The authors declare no competing financial interest.

\section{REFERENCES}

(1) Althouse, R.; Huff, J.; Tomatis, L.; Wilbourn, J. An evaluation of chemicals and industrial processes associated with cancer in humans based on human and animal data: IARC Monographs Vol. 1 to 20. Cancer Res. 1980, 40, 1-12.

(2) Williams, J. H.; Phillips, T. D.; Jolly, P. E.; Stiles, J. K.; Jolly, C. M.; Aggarwal, D. Human aflatoxicosis in developing countries: a review of toxicology, exposure, potential health consequences, and interventions. Am. J. Clin. Nutr. 2004, 80, 1106-1122.

(3) Nesbitt, B. F.; O’Kelly, J.; Sargeant, K.; Sheridan, A. Aspergillus flavus and turkey $\mathrm{X}$ disease. Toxic metabolites of Aspergillus flavus. Nature 1962, 195, 1062-1063.

(4) Van der Zijden, A. S.; Koelensmid, W. A. A. B.; Boldingh, J.; Barrett, C. B.; Ord, W. O.; Philp, J. Isolation in crystalline form of a toxin responsible for Turkey X disease. Nature 1962, 195, 1060-1062.

(5) Aisyah, S.; Gruppen, H.; Slager, M.; Helmink, B.; Vincken, J.-P. Modification of prenylated stilbenoids in peanut (Arachis hypogaea) seedlings by the same fungi that elicited them: The fungus strikes back. J. Agric. Food Chem. 2015, 63, 9260-9268.

(6) Sobolev, V. S. Production of phytoalexins in peanut (Arachis hypogaea) seed elicited by selected microorganisms. J. Agric. Food Chem. 2013, 61, 1850-1858.

(7) Wotton, H. R.; Strange, R. N. Circumstantial evidence for phytoalexin involvement in the resistance of peanuts to Aspergillus flavus. Microbiology 1985, 131, 487-494.

(8) Subba Rao, P. V.; Strange, R. N. Chemistry, biology, and role of groundnut phytoalexins in resistance to fungal attack. In Handbook of Phytoalexin Metabolism and Action; Daniel, M., Purkayastha, R. P., Eds.; Marcel Dekker, Inc.: New York, NY, 1995; pp 199-227.

(9) Wang, H.; Lei, Y.; Yan, L.; Cheng, K.; Dai, X.; Wan, L.; Guo, W.; Cheng, L.; Liao, B. Deep sequencing analysis of transcriptomes in Aspergillus flavus in response to resveratrol. BMC Microbiol. 2015, 15, 182.

(10) Kim, J. H.; Yu, J.; Mahoney, N.; Chan, K. L.; Molyneux, R. J.; Varga, J.; Bhatnagar, D.; Cleveland, T. E.; Nierman, W. C.; Campbell, B. C. Elucidation of the functional genomics of antioxidant-based inhibition of aflatoxin biosynthesis. Int. J. Food Microbiol. 2008, 122, 49-60.

(11) Kim, J. H.; Campbell, B. C.; Yu, J.; Mahoney, N.; Chan, K. L.; Molyneux, R. J.; Bhatnagar, D.; Cleveland, T. E. Examination of fungal stress response genes using Saccharomyces cerevisiae as a model system: targeting genes affecting aflatoxin biosynthesis by Aspergillus flavus Link. Appl. Microbiol. Biotechnol. 2005, 67, 807-815.

(12) Wang, H.; Huang, J.; Lei, Y.; Yan, L.; Wang, S.; Jiang, H.; Ren, X.; Lou, Q.; Liao, B. Relationship of resveratrol content and resistance to aflatoxin accumulation caused by Aspergillus flavus in peanut seeds. Zuowu Xuebao 2012, 38, 1875-1883.

(13) Sobolev, V. S. Localized production of phytoalexins by peanut (Arachis hypogaea) kernels in response to invasion by Aspergillus species. J. Agric. Food Chem. 2008, 56, 1949-1954.

(14) Sobolev, V. S.; Khan, S. I.; Tabanca, N.; Wedge, D. E.; Manly, S. P.; Cutler, S. J.; Coy, M. R.; Becnel, J. J.; Neff, S. A.; Gloer, J. B. Biological activity of peanut (Arachis hypogaea) phytoalexins and selected natural and synthetic stilbenoids. J. Agric. Food Chem. 2011, $59,1673-1682$.

(15) Sobolev, V. S.; Krausert, N. M.; Gloer, J. B. New monomeric stilbenoids from peanut (Arachis hypogaea) seeds challenged by an Aspergillus flavus strain. J. Agric. Food Chem. 2016, 64, 579-584.

(16) Sobolev, V. S.; Cole, R. J.; Dorner, J. W.; Yagen, B. Isolation, purification, and liquid chromatographic determination of stilbene phytoalexins in peanuts. J. AOAC Int. 1995, 78, 1177-1182.

(17) Sobolev, V. S.; Neff, S. A.; Gloer, J. B. New stilbenoids from peanut (Arachis hypogaea) seeds challenged by an Aspergillus caelatus strain. J. Agric. Food Chem. 2009, 57, 62-68.

(18) Sobolev, V. S.; Dorner, J. W. Cleanup procedure for determination of aflatoxins in major agricultural commodities by liquid chromatography. J. AOAC Int. 2002, 85, 642-645. 
(19) Sobolev, V. S.; Deyrup, S. T.; Gloer, J. B. New peanut (Arachis hypogaea) phytoalexin with prenylated benzenoid and but-2-enolide moieties. J. Agric. Food Chem. 2006, 54, 2111-2115. 